\title{
MANIFESTAÇÃO DA ORIENTAÇÃO EMPREENDEDORA EM UMA ORGANIZAÇÃO SEM FINS LUCRATIVOS
}

Artigo recebido em: 03/12/2014. Artigo aprovado em: 26/06/2015.

Fabrício Martins Lacerda - Universidade Nove de Julho - UNINOVE ${ }^{1}$ Ana Claudia Belfort - Universidade Nove de Julho - UNINOVE ${ }^{2}$ Cristina Dai Prá Martens - Universidade Nove de Julho - UNINOVE ${ }^{3}$

Resumo: A Orientação Empreendedora constitui importante tema de estudo no contexto organizacional. Porém, em organizações sem fins lucrativos, esse conceito ainda não está adequadamente estabelecido. Nesse sentido, este artigo busca analisar a manifestação da Orientação Empreendedora nas ações de uma organização sem fins lucrativos à luz do modelo de Morris, Webb e Franklin (2011). Os resultados permitiram identificar a manifestação das dimensões inovatividade, proatividade e assunção de riscos nas ações realizadas pela organização diante das suas necessidades ou busca pelas oportunidades (motivação, processos e resultados). Conclui-se que a organização é "socialmente e comercialmente empreendedora", pois tem enfatizado o empreendedorismo tanto em relação à sua missão social e como ela é alcançada, quanto às parcerias comerciais com organizações públicas e privada.

Palavras-chave: Orientação Empreendedora; Empreendedorismo; Organizações sem fins lucrativos; Associações de Profissionais Médicos.

\section{MANIFESTATION OF ENTREPRENEURIAL ORIENTATION ON A NONPROFIT ORGANIZATION}

\begin{abstract}
The Entrepreneurial Orientation is an important field of study in the organizational context. However, in nonprofit organizations, is not yet properly established. In this sense, this article aims to analyze the manifestation of Entrepreneurial Orientation in the actions of a nonprofit organization in light of Morris, Webb and Franklin (2011) model. The results showed the manifestation dimensions of innovativeness, proactiveness and risk-taking in the actions taken by the organization front their needs or search for opportunities (motivation, processes and outcomes). It is concluded that the organization is "socially and

\footnotetext{
${ }^{1}$ Endereço: Av. Francisco Matarazzo, 612 - Prédio C - 1ํandar. Água Branca, São Paulo - SP, CEP: 05001-100. E-mail: fabriciomlacerda@gmail.com.

${ }^{2}$ E-mail: belfortanaclauida@gmail.com.

${ }^{3}$ E-mail: cristinadm@uninove.br.
}

LACERDA, F. M.; BELFORT, A. C.; MARTENS, C. D. P. Manifestação da Orientação Empreendedora em uma organização sem fins lucrativos. Revista de

Empreendedorismo e Gestão de Pequenas Empresas, v.4, n.2, 2015. 
commercially entrepreneurial", it has emphasized entrepreneurship both in relation to its social mission and how it is achieved, for the business partnerships with public and private.

Keywords: Entrepreneurial Orientation; Entrepreneurship; Nonprofit Organizations; Association of Medical Professionals.

\section{Introdução}

Apesar de ainda ser considerado um campo de estudos relativamente novo, o tema empreendedorismo tem apresentado um crescimento acelerado nas últimas décadas, tanto no contexto organizacional como no meio acadêmico, permeando diversas pesquisas a seu respeito (SHORT; KETCHEN; COMBS; IRELAND, 2010).

Pesquisas relacionadas ao empreendedorismo têm propiciado aos seus pesquisadores o uso de vários conceitos em diferentes contextos, bem como permitido o desenvolvimento de novos estudos na área (GRÉGOIRE; NÖEL; DÉRY; BÉCHARD, 2006; SCHILDT; ZAHRA; SILLANPÄÄ, 2006). Neste âmbito, destaca-se a pesquisa sobre empreendedorismo no campo organizacional, conhecida como postura empreendedora de uma organização (COVIN; SLEVIN, 1989) e como Orientação Empreendedora - OE (LUMPKIN; DESS, 1996).

A OE (Orientação Empreendedora) constitui uma das poucas áreas de pesquisa em empreendedorismo com um cumulativo corpo de conhecimento em desenvolvimento (COVIN; LUMPKIN, 2011; RAUCH; WIKLUND; LUMPKIN; FRESE, 2009; WALES; MONSEN; MCKELVIE, 2011). Trata-se de um dos constructos mais estudados na literatura sobre empreendedorismo com inúmeras definições, muitas das quais incompatíveis entre si (GEORGE; MARINO, 2011).

No Brasil, também é possível identificar um crescimento considerável, principalmente nos últimos anos, envolvendo o estudo do tema empreendedorismo. Isso devido à sua importância para a prática administrativa (FREITAS; MARTENS; BOISSIN; BEHR, 2012). Outros estudiosos, tais como Fernandes e Santos (2008), Silva, Gomes e Correia (2009), Martens, Freitas e Andres (2011), França, Saraiva e Hashimoto (2012), Hashimoto e Belê (2014), 
também possuem estudos com essa temática no contexto brasileiro, mas em segmentos estritamente econômicos.

A existência de diferenças em contextos específicos deve ser considerada na verificação do empreendedorismo nas atividades de uma organização (MORRIS; WEBB; FRANKLIN, 2011). Por exemplo, os constructos empreendedorismo social (MORT; WEERAWARDENA; CARNEGIE, 2003), orientação empreendedora (MILLER, 1983; COVIN; SLEVIN, 1989) e orientação empreendedora no contexto não lucrativo (MORRIS; WEBB; FRANKLIN, 2011), utilizam as mesmas dimensões de inovatividade, assunção de riscos e proatividade para caracterizar a manifestação do empreendedorismo nas organizações. Porém, a missão da organização pode diferenciar os empreendedores sociais dos comerciais, com ou sem finalidade lucrativa (DESS, 1998; DACIN; DACIN; MATEAR, 2010), além de suas características operacionais (MORT; WEERAWARDENA; CARNEGIE, 2003).

Pesquisas a respeito do empreendedorismo no contexto não lucrativo também passaram a fazer parte de estudos que buscam entender como se manifesta a OE em organizações sem fins lucrativos (OSFL), a exemplo de Morris, Webb e Franklin (2011) e Lumpkin, Moss, Gras, Kato e Amezcua (2011). No entanto, a base teórica para o empreendedorismo dentro de OSFL não tem sido adequadamente estabelecida.

A lógica do empreendedorismo é menos evidente nesse contexto. Podese questionar, por exemplo, as implicações da inovação e assunção de risco, em razão da finalidade social e dos múltiplos stakeholders da empresa. Operacionalmente, as formas que o empreendedorismo pode tomar e as implicações de seus diferentes níveis não são claras em um contexto sem fins lucrativos (MORRIS; COOMBES; SCHINDEHUTTE; ALLEN, 2007).

Nesse cenário, considerando que a OE é tema ainda pouco estudado no contexto não lucrativo brasileiro, busca-se responder a seguinte questão: quais as ações que caracterizam a manifestação da orientação empreendedora em uma organização sem fins lucrativos? Portanto, o objetivo principal deste estudo é analisar a manifestação da orientação empreendedora nas ações de uma LACERDA, F. M.; BELFORT, A. C.; MARTENS, C. D. P. Manifestação da Orientação Empreendedora em uma organização sem fins lucrativos. Revista de Empreendedorismo e Gestão de Pequenas Empresas, v.4, n.2, 2015. 
organização sem fins lucrativos, à luz do modelo de Morris, Webb e Franklin (2011). Para isso, adotou-se como objeto de estudo uma Associação de Profissionais Médicos.

Esta associação faz parte das dezessete mil associações profissionais que desenvolvem:

[...] as atividades de organizações e associações constituídas em relação a uma profissão, técnica ou área de conhecimento, centrada em: difusão de informação, estabelecimento e fiscalização do cumprimento de normas profissionais e representação perante órgãos de administração pública (FASFIL, 2012, p. 170).

O estudo das Fundações Privadas e Associações sem Fins Lucrativos (FASFIL) concluiu que no Brasil existiam, em 2010, mais de 290 mil organizações, entre elas as Associações Profissionais. Nesta classificação, faz parte a Associação de Profissionais Médicos (APM), que representa uma área da medicina brasileira em âmbito nacional e internacional.

O fato da referida Associação não possuir fins lucrativos não a exime de contar com um direcionamento estratégico de suas ações e da necessidade de geração de receita para sustentar suas operações, sejam elas sociais ou não. Nessa linha, o conhecimento acerca de como se manifesta a OE tende a contribuir no sentido de fornecer subsídios às Associações Profissionais para a prática da inovatividade, assunção de risco e proatividade, que se relacionam ao melhor desempenho da organização (RAUCH et al., 2009).

Após esta introdução, a próxima seção tem como foco a revisão da literatura a respeito do empreendedorismo no nível organizacional e da manifestação da orientação empreendedora no contexto não lucrativo. Em seguida, é apresentado o método adotado neste estudo. Na sequência, faz-se a análise dos resultados e, por fim, as considerações finais são apresentadas.

LACERDA, F. M.; BELFORT, A. C.; MARTENS, C. D. P. Manifestação da Orientação Empreendedora em uma organização sem fins lucrativos. Revista de

Empreendedorismo e Gestão de Pequenas Empresas, v.4, n.2, 2015. 


\section{Referencial teórico}

Nesta seção, a literatura é revisitada e os aspectos conceituais em relação ao empreendedorismo no nível organizacional são retomados, sobretudo os da Orientação Empreendedora no contexto sem fins lucrativos, com vistas a destacar as principais características que levam a sua manifestação nas organizações.

\section{Empreendedorismo no contexto das organizações}

As diferenças de empreendedorismo nas organizações podem ser atribuídas a combinações de fatores individuais, organizacionais e ambientais (MILLER, 1983; LUMPKIN; DESS, 1996). O progresso no estudo acerca do empreendedorismo apresenta implicações positivas para seu maior desenvolvimento teórico e metodológico, o que pode propiciar melhor compreensão do ponto de vista organizacional (SLEVIN; TERJESEN, 2011).

O estudo de Dess (1998), por exemplo, diferencia os empreendedores sociais dos comerciais em termos de sua missão, que é explícita e central, capaz de afetar o modo como os empreendedores sociais percebem e avaliam as oportunidades. Mort, Weerawardena e Carnegie (2003) complementam que as organizações sociais diferem de suas contrapartes comerciais em termos de suas características operacionais, originando o constructo Empreendedorismo Social.

Apesar de alguns estudiosos ignorarem o aspecto econômico do Empreendedorismo Social, Dacin, Dacin e Matear (2010) acreditam que a criação de valor social está intimamente ligada aos resultados econômicos, pois produzem recursos financeiros que permitem cumprir sua missão social. Para esses autores, a definição que detém o maior potencial para a construção de uma compreensão única do Empreendedorismo Social é aquela que incide os

LACERDA, F. M.; BELFORT, A. C.; MARTENS, C. D. P. Manifestação da Orientação Empreendedora em uma organização sem fins lucrativos. Revista de

Empreendedorismo e Gestão de Pequenas Empresas, v.4, n.2, 2015. 
resultados positivos ou negativos das empresas sobre a missão social, visando à criação de valor social.

Mort, Weerawardena e Carnegie (2003) argumentam que o Empreendedorismo Social pode ser conceituado como um constructo multidimensional, refletindo as características operacionais principais das organizações sociais, nas dimensões inovatividade, proatividade e assunção de riscos. No entanto, os autores ressaltam a centralidade da missão social no Empreendedorismo Social, mas também observam a inadequação de uma única conceituação dimensional para capturar a natureza complexa do Empreendedorismo Social.

Para Lumpkin e Dess (1996), a existência de empreendedorismo nas organizações decorre de sua Orientação Empreendedora que, por sua vez, é influenciada por fatores individuais, organizacionais e ambientais. Tal afirmação é corroborada por Shane e Venkataraman (2000) ao asseverarem que o empreendedorismo é influenciado não somente por características pessoais, mas também por situações e ambientes aos quais as organizações pertencem.

Para esses autores, o comportamento empreendedor surge como uma resposta às ameaças e oportunidades do ambiente. Miller (1983) afirma que variáveis ambientais, estruturais, estratégicas e a própria personalidade do líder podem influenciar a forma como o empreendedorismo se desenvolve no contexto organizacional.

Segundo Freitas et al. (2012, p. 164), “a OE pode ser conceituada como a gestão do processo empreendedor, retratada em métodos, práticas e estilos de gestão ou de tomada de decisão usados para agir de forma empreendedora". A literatura apresenta uma ampla gama de definições para OE. No entanto, duas abordagens são apontadas como as principais e, consequentemente, mais utilizadas nas pesquisas a respeito desse constructo (GEORGE; MARINO, 2011), conforme demonstra o Quadro 1.

LACERDA, F. M.; BELFORT, A. C.; MARTENS, C. D. P. Manifestação da Orientação Empreendedora em uma organização sem fins lucrativos. Revista de

Empreendedorismo e Gestão de Pequenas Empresas, v.4, n.2, 2015. 
Quadro 1 - Duas principais abordagens a respeito de OE e suas dimensões.

\begin{tabular}{|c|c|l|}
\hline Autores & Constructo & \multicolumn{1}{|c|}{ Dimensões da OE } \\
\hline $\begin{array}{c}\text { Miller (1983) e } \\
\text { Covin e Slevin } \\
(1989)\end{array}$ & Unidimensional & $\begin{array}{l}\text { Inovatividade; Assunção de riscos; } \\
\text { Proatividade. }\end{array}$ \\
\hline $\begin{array}{c}\text { Lumpkin e Dess } \\
(1996)\end{array}$ & Multidimensional & $\begin{array}{l}\text { Inovatividade; Assunção de riscos; } \\
\text { Proatividade; Autonomia; Agressividade } \\
\text { competitiva. }\end{array}$ \\
\hline
\end{tabular}

Fonte: Os autores (2015)

A Orientação Empreendedora de uma organização, como um constructo unidimensional, é demonstrada à proporção em que os gestores estão dispostos a favorecer mudanças e inovação, a assumir riscos e a atuar proativamente à frente de outras organizações (COVIN; SLEVIN, 1989). Nessa abordagem, as três dimensões devem estar presentes na organização em certa intensidade.

Lumpkin e Dess (1996), com base em Miller (1983), acrescentaram mais duas dimensões à OE (autonomia e agressividade competitiva), tornando esse construto multidimensional. A presença das dimensões em maior ou menor intensidade retrata o quanto a organização é orientada ao empreendedorismo. $\mathrm{Na}$ abordagem multidimensional, a OE pode ser constituída por diferentes combinações das cinco dimensões, ou mesmo por apenas algumas delas, a depender de fatores externos, internos ou características dos líderes da organização (LUMPKIN; DESS, 1996).

Os constructos Empreendedorismo Social (MORT; WEERAWARDENA; CARNEGIE, 2003) e Orientação Empreendedora (COVIN; SLEVIN, 1989) apresentam similaridades em termos de algumas dimensões de análise do empreendedorismo no contexto organizacional, a saber: inovatividade, assunção de riscos e proatividade. As dimensões autonomia e agressividade competitiva, contudo, parecem ser tratadas com menor ênfase pela literatura de Empreendedorismo Social.

Esse aspecto é apresentado de forma mais detalhada na próxima seção, onde são revisitadas algumas abordagens sobre a manifestação da Orientação Empreendedora no contexto não lucrativo.

LACERDA, F. M.; BELFORT, A. C.; MARTENS, C. D. P. Manifestação da Orientação Empreendedora em uma organização sem fins lucrativos. Revista de

Empreendedorismo e Gestão de Pequenas Empresas, v.4, n.2, 2015. 


\section{Orientação empreendedora no contexto sem fins lucrativos}

O empreendedorismo tem um papel legítimo nas organizações sem fins lucrativos e o ambiente de trabalho pode ser projetado para afetar e gerar níveis de empreendedorismo mais elevados, que poderão ser alcançados em ambientes de trabalho no qual os erros são tratados como oportunidades de aprendizagem; a iniciativa individual é incentivada; a ênfase é na excelência; as pessoas trabalham para o bem da equipe; e há uma constante busca pela melhoria das operações (MORRIS et al., 2007).

$\mathrm{Na}$ ausência do potencial de lucros apropriados, as organizações sem fins lucrativos perseguem o empreendedorismo por três razões principais: (1) a necessidade de geração de receita maior ou uma maior eficiência interna para sustentar financeiramente as operações; (2) uma sensação de que as exigências em termos de necessidade social precisam ultrapassar a capacidade da organização para atender a essa demanda; e (3) mudanças no ambiente que criam oportunidades de criação de valores sociais que não existiam anteriormente (BADELT, 1997; DEES, 1998; PEARCE; FRITZ; DAVIS, 2010; ZAHRA; GEDAJLOVIC; NEUBAUM; SHULMAN, 2009).

No Quadro 2 estão relacionadas as dimensões utilizadas por pesquisadores na investigação da OE em diferentes contextos de OSFL.

LACERDA, F. M.; BELFORT, A. C.; MARTENS, C. D. P. Manifestação da Orientação Empreendedora em uma organização sem fins lucrativos. Revista de Empreendedorismo e Gestão de Pequenas Empresas, v.4, n.2, 2015. 
Quadro 2 - Estudos empíricos que examinaram a OE no contexto não lucrativo.

\begin{tabular}{|c|c|c|c|c|c|c|}
\hline \multirow[t]{2}{*}{ Autores } & \multirow[t]{2}{*}{ Contexto não Lucrativo } & \multicolumn{5}{|c|}{$\begin{array}{l}\text { Dimensões da } \\
\text { Orientação } \\
\text { Empreendedora }\end{array}$} \\
\hline & & IN & AR & PR & AU & $\mathbf{A C}$ \\
\hline Morris e Joyce (1998) & Bancos de sangue & $X$ & $x$ & $x$ & & \\
\hline $\begin{array}{c}\text { Caruana, Ewing e } \\
\text { Ramaseshan (2002) }\end{array}$ & $\begin{array}{c}\text { Entidades do setor público } \\
\text { australiano }\end{array}$ & $X$ & $X$ & $X$ & & \\
\hline Bhuian et al. (2005) & Hospitais & $X$ & $X$ & $X$ & & \\
\hline $\begin{array}{l}\text { Voss, Voss e Moorman } \\
(2005)\end{array}$ & Indústria de teatro profissional & $X$ & $X$ & $\mathrm{X}$ & $X$ & $X$ \\
\hline Morris et al. (2007) & $\begin{array}{c}\text { Serviço social no interior de } \\
\text { New York }\end{array}$ & $X$ & $X$ & $X$ & & \\
\hline Coombes et al. (2009) & Organizações de arte & $X$ & $x$ & $\mathrm{X}$ & & \\
\hline $\begin{array}{c}\text { Pearce, Fritz e Davis } \\
(2010)\end{array}$ & Congregações religiosas & $X$ & $X$ & $X$ & $X$ & $x$ \\
\hline $\begin{array}{l}\text { Helm e Andersson } \\
\text { (2010) }\end{array}$ & $\begin{array}{l}\text { Organizações na área } \\
\text { metropolitana da cidade do } \\
\text { Kansas }\end{array}$ & $\mathrm{X}$ & $X$ & $\mathrm{X}$ & & \\
\hline Davis et al. (2011) & $\begin{array}{c}\text { Lares de idosos na Florida com } \\
\text { e sem fins lucrativos }\end{array}$ & $X$ & $X$ & $X$ & & \\
\hline
\end{tabular}

Fonte: Adaptado de Morris, Webb e Franklin (2011).

Nota: $I N$ = Inovatividade; $A R=$ Assunção de Riscos; $P R=$ Proatividade; $A U$ = Autonomia; $A C=$ Agressividade Competitiva .

Por meio do Quadro 2 é possível observar que predominou, na realização dos estudos, a utilização do constructo unidimensional da OE proposto por Covin e Slevin (1989). Apenas as pesquisas de Pearce, Fritz e Davis (2010) e Voss, Voss e Moorman (2005) adotaram a visão multidimensional de Lumpkin e Dess (1996). Porém, esses autores não justificaram a escolha de uma ou outra abordagem para verificar a OE no contexto sem fins lucrativos.

Diversos estudos empíricos que relacionaram a $\mathrm{OE}$ ao contexto das organizações sem fins lucrativos levantaram questões sobre se a OE tem uma relação diferente com o desempenho nesse contexto ou se sua manifestação possui forma distinta nessas organizações, em comparação ao contexto de organizações com fins lucrativos. Porém, é preciso ressaltar que as escalas tradicionalmente utilizadas nos estudos sobre OE (MILLER, 1983; COVIN; SLEVIN, 1989) não capturaram a natureza mais complexa e multifacetada da OE LACERDA, F. M.; BELFORT, A. C.; MARTENS, C. D. P. Manifestação da Orientação Empreendedora em uma organização sem fins lucrativos. Revista de Empreendedorismo e Gestão de Pequenas Empresas, v.4, n.2, 2015. 
no contexto sem fins lucrativos, nas dimensões inovatividade, assunção de riscos e proatividade (MORRIS; WEBB; FRANKLIN, 2011).

Morris, Webb e Franklin (2011) enfatizam a existência de diferenças, mesmo que sutis, mas também primordiais, que devem ser consideradas ao verificar essas manifestações em contextos específicos. Para Morris et al. (2007), a OE tem implicações importantes em organizações sem fins lucrativos, embora o seu papel possa ser mais complexo do que em organizações puramente econômicas.

Ao considerar que as pesquisas em $\mathrm{OE}$ têm se concentrado nas dimensões inovatividade, assunção de riscos e proatividade, bem como a análise dos resultados de diferentes estudos, Morris, Webb e Franklin (2011) identificaram a necessidade de repensar o constructo unidimensional da OE no contexto não lucrativo. Esses autores propõem uma nova abordagem para capturar a manifestação da OE em OSFL, como apresentada na seção seguinte.

\section{Modelo de Morris, Webb e Franklin (2011)}

Segundo Morris, Webb e Franklin (2011, p. 947), os "estudiosos têm tido interesse em empreendedorismo em organizações sem fins lucrativos e têm atraído a Orientação Empreendedora como uma ferramenta metodológica para o avanço do conhecimento nesse domínio". De acordo com os autores, para a compreensão do empreendedorismo e da aplicação da OE nesse contexto, devem ser considerados: 1) motivação - oportunidades vinculadas à necessidade de servir a um propósito social; ii) processos - motivações baseadas em missão social diferenciam seus processos; iii) resultados - métricas de desempenho incluem tanto indicadores sociais quanto financeiros.

Para abordar a capacidade de capturar a verdadeira natureza da OE, Morris, Webb e Franklin (2011) basearam-se em três questões: (1) o significado de OE no contexto sem fins lucrativos, em particular, em termos da sua definição e dimensionalidade; (2) o significado de cada uma das dimensões da $\mathrm{OE}$ LACERDA, F. M.; BELFORT, A. C.; MARTENS, C. D. P. Manifestação da Orientação Empreendedora em uma organização sem fins lucrativos. Revista de Empreendedorismo e Gestão de Pequenas Empresas, v.4, n.2, 2015. 
(inovatividade, proatividade e assunção de riscos); e (3) o significado das relações entre cada uma dessas dimensões.

A primeira, a inovatividade, é a capacidade de inovação. Nas OSFLs, a motivação orientada para a missão social pode levar essas entidades a buscarem inovações para proporcionar benefícios mais eficazes e ampliá-los para um mercado maior. Essa dimensão é composta pelas seguintes subdimensões: a) ênfase na inovação direcionada ao cumprimento da missão principal, aumentando a eficiência, servindo mais indivíduos, ou melhorando o que é feito para esses indivíduos; b) ênfase na inovação direcionada à geração de novas fontes de receita, como a venda de produtos ou o lançamento de empreendimentos complementares ou independentes para a missão social; c) ênfase na inovação direcionada tanto à geração de receitas e realização da missão em conjunto com outra (MORRIS; WEBB; FRANKLIN, 2011).

A proatividade tem como essência o grau em que uma organização apoia o desenvolvimento de antecipação e implementação de inovações antes de outros, permitindo, assim, o crescimento e desempenho aprimorado. Essa dimensão é composta pelas seguintes subdimensões: a) promulgação da mudança do objeto social, como é conseguida em relação a organizações com missões semelhantes; b) promulgação da mudança na forma como as necessidades financeiras são atendidas em relação às organizações com missões semelhantes; c) promulgação de mudança em relação às expectativas das partes interessadas (MORRIS; WEBB; FRANKLIN, 2011).

Já a assunção de risco em empresas com fins lucrativos geralmente associa níveis de risco com os retornos futuros. A equação de risco em organizações sem fins lucrativos é mais difícil de quantificar. Essa dimensão é composta pelas seguintes subdimensões: a) disposição para tomar ações que incorrem probabilidade significativa e magnitude da perda na quantidade de impacto social alcançado pela organização; b) disposição para adotar ações que incorrem probabilidade significativa e magnitude de perda financeira; c) disposição para adotar ações que incorrem probabilidade significativa e

LACERDA, F. M.; BELFORT, A. C.; MARTENS, C. D. P. Manifestação da Orientação Empreendedora em uma organização sem fins lucrativos. Revista de

Empreendedorismo e Gestão de Pequenas Empresas, v.4, n.2, 2015. 
magnitude de perda de apoio não financeiro das partes interessadas (MORRIS; WEBB; FRANKLIN, 2011).

No Quadro 3 está resumida a abordagem proposta por Morris, Webb e Franklin (2011) para a compreensão da manifestação da OE no contexto sem fins lucrativos.

Quadro 3 - Orientação Empreendedora em organizações sem fins lucrativos.

\begin{tabular}{|c|c|c|}
\hline Dimensões & $\begin{array}{l}\text { Subdimensão/ênfase da } \\
\text { dimensão }\end{array}$ & $\begin{array}{l}\text { Necessidade/ } \\
\text { Oportunidade }\end{array}$ \\
\hline \multirow{3}{*}{$\begin{array}{l}\text { Inovatividade - ênfase na inovação } \\
\text { direcionada }\end{array}$} & Missão principal & \multirow{9}{*}{$\begin{array}{l}\text { Motivação } \\
\text { Processos } \\
\text { Resultados }\end{array}$} \\
\hline & Novas fontes de receita & \\
\hline & Receita e missão & \\
\hline \multirow{3}{*}{$\begin{array}{c}\text { Proatividade - promulgação da } \\
\text { mudança }\end{array}$} & Objetivo social & \\
\hline & Financeiro & \\
\hline & Stakeholders & \\
\hline \multirow{3}{*}{$\begin{array}{c}\text { Assunção de Risco - disposição para } \\
\text { assumir ações de risco }\end{array}$} & Impacto social & \\
\hline & Perda financeira & \\
\hline & Impacto nos stakeholders & \\
\hline
\end{tabular}

Fonte: Elaborado com base em Morris, Webb e Franklin (2011).

As dimensões de inovatividade, proatividade e assunção de risco são mais complexas e multifacetadas no contexto não lucrativo, compostas por três subdimensões em cada uma delas. Mais precisamente, as subdimensões definidas para cada dimensão buscam captar o significado do empreendedorismo e da OE nas OSFLs. Segundo Morris, Webb e Franklin (2011, p. 961), cada uma das subdimensões "destina-se a capturar um espaço distinto e conceitual a ser mutuamente exclusivo de outras subdimensões". Ou seja, "cada subdimensão pode existir sem relação com outras subdimensões". Mas os autores têm a expectativa de "que as relações entre subdimensões possam existir".

Uma tipologia de OSFL, com base em níveis de Empreendedorismo Social e Comercial variável, foi utilizada para ilustrar a natureza multifacetada da OE no contexto sem fins lucrativos, demonstrando a necessidade de uma compreensão mais abrangente desse cenário (MORRIS; WEBB; FRANKLIN, 2011). A Figura 1 abaixo evidencia isso.

LACERDA, F. M.; BELFORT, A. C.; MARTENS, C. D. P. Manifestação da Orientação Empreendedora em uma organização sem fins lucrativos. Revista de

Empreendedorismo e Gestão de Pequenas Empresas, v.4, n.2, 2015. 
whreger

Empreendedorismo Comercial

Figura 1 - Tipologia das OSFLs baseada no nível de Empreendedorismo Social e Comercial

Fonte: Adaptado de Morris, Webb e Franklin (2011).

As OSFLs poderão ser classificadas em um dos quadrantes da tipologia (Figura 1), segundo algumas características (MORRIS; WEBB; FRANKLIN, 2011). Quadrante 1: podem ser organizações menores com foco no trabalho voluntário, permanecendo fiel à missão social, raramente assumem riscos sociais ou comerciais e não agem proativamente. Quadrante 2: tem uma missão social, torna-se mais proativa de acordo com as necessidades dos clientes e busca equilibrar os riscos, tendo menos impacto social e tornando suas ações mais viáveis financeiramente. Quadrante 3: as OSFLs possuem uma base financeira sólida e são ativamente envolvidas em abordagens tradicionais para angariar fundos. Ao mesmo tempo, buscam expandir o alcance geográfico da organização, demonstrando altos níveis de empreendedorismo social, que servem para promover a missão. Quadrante 4: enfatizam o empreendedorismo, tanto em relação à sua missão ou como ela é alcançada, quanto às operações comerciais. Como um empreendedor social, desenvolve ações de inovação, realiza avaliações no seu contexto e projeta programas e políticas. Mantêm parcerias financeiras com os setores públicos e privados no desenvolvimento das ações, assumindo riscos e agindo proativamente. Possuem diversas iniciativas sociais e

LACERDA, F. M.; BELFORT, A. C.; MARTENS, C. D. P. Manifestação da Orientação Empreendedora em uma organização sem fins lucrativos. Revista de

Empreendedorismo e Gestão de Pequenas Empresas, v.4, n.2, 2015. 
comerciais, como a venda de produtos, realização de eventos, patrocínios corporativos e até programas educativos.

Os autores concluem que essa tipologia ajuda a esclarecer as possíveis deficiências quando se confia na abordagem convencional de OE no contexto não lucrativo. Logo, a probabilidade de se avaliar erroneamente a OE é maior com organizações no quadrante (4) e menor no quadrante (1).

Por fim, Morris, Webb e Franklin (2011) destacam que o empreendedorismo tornou-se um importante meio através do qual as OSFLs poderão melhorar a sua eficiência e eficácia no cumprimento das oportunidades.

\section{Procedimentos metodológicos}

A presente pesquisa possui caráter exploratório, pois buscou definir o problema com maior precisão e identificar sentidos relevantes de ação na obtenção de dados adicionais antes de poder desenvolver uma abordagem (MALHOTRA, 2006).

Adotou-se a técnica de análise qualitativa com a finalidade de caracterizar a descrição, compreensão e interpretação de fatos e fenômenos (MARTINS; THEÓPHILO, 2009). Por se tratar de uma investigação empírica de um fenômeno contemporâneo, adotou-se o estudo de caso como estratégia de pesquisa (YIN, 2010).

Nesse sentido, este estudo busca analisar a manifestação da orientação empreendedora nas ações de uma organização sem fins lucrativos, à luz do modelo de Morris, Webb e Franklin (2011), adotando-se como objeto de estudo, uma Associação de Profissionais Médicos. Resumidamente, o estudo realizado pode ser visualizado na Figura 2 a seguir.

LACERDA, F. M.; BELFORT, A. C.; MARTENS, C. D. P. Manifestação da Orientação Empreendedora em uma organização sem fins lucrativos. Revista de

Empreendedorismo e Gestão de Pequenas Empresas, v.4, n.2, 2015. 


\section{QUESTÃO DE PESQUISA}

Quais as ações que caracterizam a manifestação da orientação empreendedora em uma organização sem fins lucrativos?

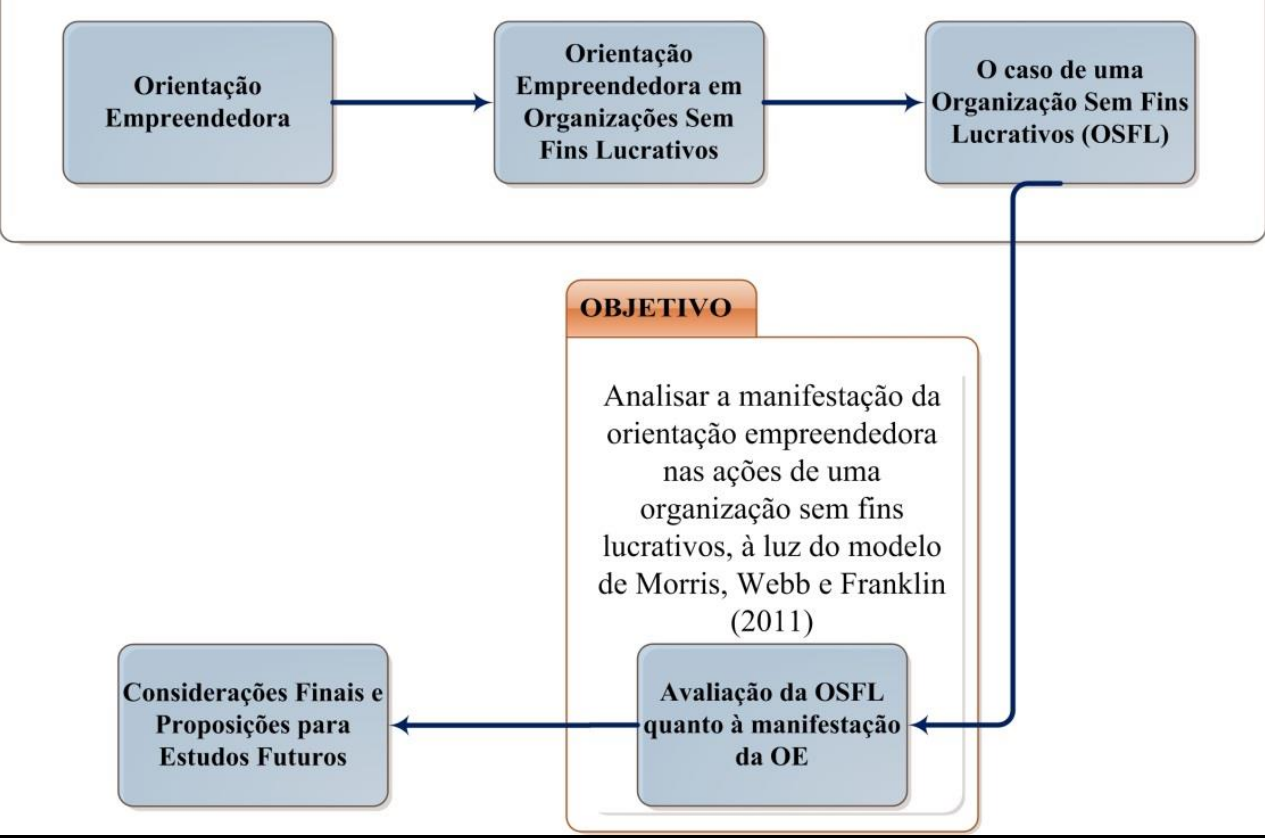

Figura 2 - Resumo do estudo

Fonte: Elaborado pelos autores.

Fundada há mais de 70 anos, a Associação de Profissionais Médicos, nome adotado neste estudo para fins de anonimato, é uma associação científica e cultural de médicos que atuam na medicina oftalmológica. De natureza privada e sem finalidade lucrativa, tem o reconhecimento de Utilidade Pública Federal. Sendo a principal entidade representativa da Oftalmologia no Brasil, desenvolve suas atividades no setor de serviços, realizando ações com finalidade social, científica, educativa e institucional, por meio de parcerias públicas e privadas.

A definição do campo de pesquisa foi motivada pelo fato da APM se destacar de outras associações profissionais ao realizar importantes ações de saúde pública nacionais em parceria com órgãos públicos, empresas privadas e outras entidades médicas. Também por desenvolver novas ações estratégicas e sistemas de gestão, objetivando maximizar a captação de recursos financeiros, o planejamento e execução de suas ações, a normatização de produtos e serviços

LACERDA, F. M.; BELFORT, A. C.; MARTENS, C. D. P. Manifestação da Orientação Empreendedora em uma organização sem fins lucrativos. Revista de Empreendedorismo e Gestão de Pequenas Empresas, v.4, n.2, 2015. 
para que a qualidade e o desempenho de suas atividades sejam constantemente melhorados.

A coleta de dados foi concretizada por meio da análise de documentos (relatórios de atividades, do Sistema de Gestão da Qualidade, jornal informativo, estatuto, regimento interno) e registros em arquivos (organograma, bases de dados de associados, financeiros e pessoal), mantidos e disponibilizados pela associação. Envolveu, ainda, a observação participante de um dos autores, que congrega o quadro funcional da associação com atuação efetiva em diversas ações desenvolvidas ao longo do tempo. Adotou-se o protocolo elaborado para coleta de dados fortemente baseado nas subdimensões propostas por Morris, Webb e Franklin (2011), descritas na seção anterior e resumidas no Quadro 3, visando à análise das dimensões da OE.

Para a análise dos dados coletados, primeiramente realizou-se a leitura dos documentos e registro em arquivos, visando à identificação de ações que caracterizassem inovatividade, assunção de riscos e proatividade, por meio das respectivas subdimensões (também com base no Quadro 3). Na sequência, os dados foram reduzidos e apresentados, seguindo com o delineamento da análise dos resultados e busca das conclusões (MARTINS; THEÓPHILO, 2009).

As evidências identificadas ao longo do tempo convergiram de modo triangular, permitindo validar os dados, por meio de diversas ações realizadas pela APM, o que representa uma estratégia de análise. A triangulação de dados também é considerada um fator importante no estudo de caso, pois utiliza múltiplas fontes de evidências (YIN, 2010).

Assim, buscou-se exemplificar como a Orientação Empreendedora se manifesta nas ações da associação estudada na prática. Em seguida, conforme sugerido por Yin (2010), para a concretização da análise dos dados, adotou-se a estratégia geral de descrição do caso, que auxilia no desenvolvimento de uma estrutura analítica descritiva para organizar o estudo de caso.

LACERDA, F. M.; BELFORT, A. C.; MARTENS, C. D. P. Manifestação da Orientação 
Resultados e análise à luz do modelo de Morris, Webb e Franklin (2011)

Nesta seção, serão apresentadas a organização e suas ações que se destacaram no cumprimento da missão e objetivos para a qual foi constituída, conforme identificado no Estatuto Social e no Regimento Interno da APM. No decorrer do relato de análise dos resultados, buscou-se identificar quais ações representam as subdimensões que caracterizam a manifestação da OE para as dimensões inovatividade, proatividade e assunção de riscos, portanto, o constructo unidimensional.

A APM é dirigida por uma diretoria executiva composta por cinco médicos eleitos por escrutínio secreto para mandato de dois anos, tendo suas atribuições determinadas no Estatuto Social e descritas no Regimento Interno da organização. Possui 14 colaboradores que são devidamente remunerados para desempenhar atividades administrativas, financeiras, assessoras e gerenciais, objetivando a prestação de serviços a cerca de 16.000 médicos associados em todo o território nacional.

Com sede na cidade de São Paulo, mantém um escritório em Brasília com a finalidade de facilitar o contato com os órgãos governamentais, com instituições federais e também com os conselhos de diversas categorias profissionais, inclusive da própria medicina, o Conselho Federal de Medicina. Tal ação de estar presente em Brasília caracteriza a dimensão proatividade, pois há uma preocupação e promulgação de mudanças junto aos seus stakeholders, principalmente no que se refere à política, à cultura e ao código de ética médica (norma reguladora da profissão médica).

A APM tem por objetivo promover a assistência médica e a saúde ocular da população, congregar e representar a especialidade oftalmológica, contribuindo para a elevação do nível técnico, científico e ético do exercício profissional dos especialistas. Na concepção dos fundadores e dos seus continuadores, esses objetivos estatutários estão intimamente ligados de tal forma que o progresso obtido em um, reflete positivamente sobre os demais.

LACERDA, F. M.; BELFORT, A. C.; MARTENS, C. D. P. Manifestação da Orientação Empreendedora em uma organização sem fins lucrativos. Revista de

Empreendedorismo e Gestão de Pequenas Empresas, v.4, n.2, 2015. 
Atualmente, 69 Cursos de Especialização para formação na especialidade são credenciados pela APM, condição obtida após o cumprimento de várias exigências em termos de titulação dos professores, carga horária e condições de ensino. A entidade também promove anualmente uma Prova Nacional para a emissão do título de especialista e para a avaliação permanente da qualidade do ensino da especialidade no Brasil (o Título de Especialista também pode ser obtido por meio de um Programa de Residência Médica).

A preocupação da APM com a formação e atualização científica do médico especialista também é manifestada pela edição de uma revista científica e do congresso que organiza anualmente. Adicionalmente, desenvolve diversos programas de educação médica continuada, com o objetivo de favorecer a constante atualização científica de seus associados.

Nesse contexto, com base nas ações listadas é possível identificar a manifestação das dimensões inovatividade e proatividade. A inovatividade é percebida por meio de sua missão social, que inclui ações educativas e de aprimoramento da especialidade. A dimensão proatividade, por sua vez, é identificada por meio de seu objetivo social, uma vez que contempla atividades de pesquisa, ensino e defesa profissional.

No Brasil, a APM se destaca na luta pela melhoria da saúde ocular da população, na prevenção da cegueira e na reabilitação visual, permitindo identificar a manifestação da dimensão assunção de riscos, em razão de campanhas voluntárias realizadas junto à população e que envolvam políticas públicas de saúde. Tais ações caracterizam a subdimensão impacto nos stakeholders.

Salienta-se que, desde o início de suas atividades, tais iniciativas são caracterizadas, principalmente, por constantes alertas às autoridades e à sociedade brasileira, mediante manifestações verbais e escritas apresentadas em eventos oftalmológicos, a exemplo de congressos, simpósios e reuniões científicas, pela promoção de campanhas de reabilitação visual e gestões junto a autoridades constituídas, órgãos públicos e instituições de ensino, entre outros.

LACERDA, F. M.; BELFORT, A. C.; MARTENS, C. D. P. Manifestação da Orientação Empreendedora em uma organização sem fins lucrativos. Revista de

Empreendedorismo e Gestão de Pequenas Empresas, v.4, n.2, 2015. 
A disponibilidade para a realização de ação social da APM foi se diversificando e se concretizando em: (i) campanhas educativas, preventivas e de reabilitação - assunção de riscos; (ii) mutirões de execução de exames e cirurgias oculares - assunção de riscos; (iii) gestões junto aos poderes públicos e aos médicos especialistas, objetivando melhorar a assistência oftalmológica à população e priorizando a prevenção da cegueira e a promoção da saúde ocular inovatividade; (iv) ações de combate à mercantilização da medicina - assunção de riscos; (v) acompanhamento e avaliação periódica das instituições credenciadas para ministrarem Cursos de Especialização nos vários Estados do Brasil - proatividade; (vi) elaboração e aplicação das provas de habilitação ao Título de Especialista - proatividade; (vii) emissão, em conjunto com a Associação Médica Brasileira, do Título de Especialista e a realização de ações para valorizá-lo de todas as formas possíveis - proatividade; e (viii) incentivo às práticas de aperfeiçoamento profissional e de intercâmbio e transmissão de conhecimento, dentre as quais se destacam os citados Cursos de Especialização e os Congressos promovidos pela Entidade - inovatividade.

A existência de tal disponibilidade corrobora com o proposto por Morris, Webb e Franklin (2011), quanto à necessidade de servir a um propósito social, ou seja, as dimensões inovatividade, proatividade e assunção de riscos são novamente identificadas por meio das seis ações listadas anteriormente.

Corroborando com a afirmação de que as três dimensões podem ser identificadas em um contexto não lucrativo (MORRIS; WEBB; FRANKLIN, 2011), sobretudo na APM analisada, uma ação merece destaque: em 2001 foi criado o Fórum Nacional de Saúde Ocular, com o objetivo de mostrar aos parlamentares e à população o que a APM tem realizado, o que está planejado, o que a legislação permite e o que precisa ser inserido/modificado na legislação para adequar a assistência oftalmológica e promover ainda mais a prevenção da cegueira.

Esse Fórum acontece periodicamente a cada dois ou três anos e, em sua quarta edição, realizada em 2012, é possível verificar, pela ação do Fórum, a sua preocupação com o impacto social e nos stakeholders das políticas de saúde

LACERDA, F. M.; BELFORT, A. C.; MARTENS, C. D. P. Manifestação da Orientação Empreendedora em uma organização sem fins lucrativos. Revista de Empreendedorismo e Gestão de Pequenas Empresas, v.4, n.2, 2015. 
pública, bem como a ação conjunta com a indústria e o governo, e a busca pela defesa profissional do mercado de trabalho do médico.

Outras ações também permitem confirmar a presença das dimensões inovatividade, proatividade e assunção de riscos, uma vez que ao longo de sua história, a APM, além de fornecer logística adequada, tem participado em ações sociais e projetos que buscam facilitar o acesso dos cegos ao mercado de trabalho. É importante destacar a parceria com a Fundação Bradesco, MicroPower e Brasil Telecom, que resultou no desenvolvimento do programa de acesso à internet para deficientes visuais, o "Virtual Vision".

A APM também tem participado ativamente de diversas frentes de trabalho, notadamente de campanhas que objetivam a melhoria das condições de saúde ocular da população brasileira e a conscientização dos vários segmentos da sociedade sobre problemas oculares e medidas preventivas, muitas vezes pela mobilização voluntária dos seus associados.

Além de ratificar a presença da unidimensionalidade proposta por Morris, Webb e Franklin (2011) para o contexto não lucrativo, verifica-se que essas ações visam proporcionar melhoria na qualidade de vida, tanto em nível cognitivo como social, na população infantil e idosa, uma vez que $85 \%$ do contato do ser humano com o mundo acontece por intermédio da visão e os problemas visuais acarretam restrições não só na aprendizagem, como também no desenvolvimento intelectual, profissional e social do indivíduo. Segundo o Censo (IBGE, 2010), no Brasil, $23,9 \%$ da população, ou seja, 45.623 .910 pessoas apresentam alguma deficiência, sendo que as deficiências visuais estão presentes em um total de 35.791.488 de pessoas.

A promoção da saúde ocular e as ações de prevenção da cegueira têm encontrado respaldo em ações isoladas de cada órgão público (Federal: Ministério da Saúde - SUS, Ministério da Educação - FNDE e INCRA; Estadual: Secretarias de Saúde e de Educação; Municipal: Secretarias de Saúde e de Educação Municipais; Policia Militar: Corpo de Bombeiros), além de instituições sociais privadas (Comunidade Solidária, Fundação Banco do Brasil, Rotary e Lions Clubes), entre outros, despertando contínuo interesse da população. Isso LACERDA, F. M.; BELFORT, A. C.; MARTENS, C. D. P. Manifestação da Orientação Empreendedora em uma organização sem fins lucrativos. Revista de Empreendedorismo e Gestão de Pequenas Empresas, v.4, n.2, 2015. 
permite afirmar que as dimensões inovatividade e assunção de riscos estão presentes por conta de ações conjuntas entre a indústria e o governo, e por ações entre diversas associações, respectivamente.

Dessa forma, a APM tem atuado em diversas frentes que investem definitivamente na saúde ocular da população, buscando melhoria nos índices de atendimento para a expressiva demanda dessa especialidade médica, por meio de uma interação administrativa e operacional entre os programas: Campanha de Reabilitação Visual Olho no Olho, Campanha de Baixa Visão, Campanha da Catarata, Campanha de Retinopatia Diabética, Campanha do Glaucoma, Campanha de Reabilitação Visual do INCRA, Campanha de Reabilitação Visual da Comunidade Solidária, Campanha de Reabilitação Visual da Fundação Banco do Brasil, Campanhas de Saúde Ocular das entidades de prestação de serviços Rotary e Lions.

Para realizar as diversas ações sociais e institucionais, a APM efetua cobrança de anuidade não compulsória com arrecadação em torno de 50\% do total de associados. Mediante esse pagamento, o médico cadastrado passa a ter direitos e obrigações conforme rege o Estatuto e o Regimento Interno da entidade. Também promove anualmente um congresso científico visando troca de informações e experiências entre os especialistas dessa área da medicina. $O$ evento torna-se uma importante fonte para captação de recursos financeiros com a cobrança de inscrições e comercialização de espaços para exposição de produtos e serviços. É possível identificar a subdimensão novas fontes de receitas (recursos próprios ou adquiridos de terceiros), pertencente à dimensão inovatividade.

Desde 2007, a APM tem apresentado seu plano anual de gestão por meio de projetos e propostas de parcerias com as empresas do setor (indústria farmacêutica e de produtos médicos). Essa forma de gestão de portfólio de projetos busca estabelecer o aporte de recursos financeiros necessários para investimento nas suas iniciativas educacionais, no aumento dos benefícios concedidos aos associados, no aprimoramento da comunicação com a classe médica e com a própria sociedade.

LACERDA, F. M.; BELFORT, A. C.; MARTENS, C. D. P. Manifestação da Orientação Empreendedora em uma organização sem fins lucrativos. Revista de

Empreendedorismo e Gestão de Pequenas Empresas, v.4, n.2, 2015. 
A realização de parcerias entre organizações (associações, indústrias e governo) confirma a manifestação de ações que levam às dimensões inovatividade, proatividade e assunção de riscos. Um exemplo diz respeito ao fato de que, a partir de 2008, empresas farmacêuticas e de produtos médicos de capital nacional e internacional passaram a patrocinar todo o portfólio de projeto planejado anualmente pela organização, sendo criado o Grupo de Parceiros Especiais (GPE).

Caracterizada como uma ação estratégica da organização, a criação do GPE é decorrente da dificuldade na captação de patrocínio. Também foi motivada pela concorrência por recursos com outras entidades, cada vez mais acirrada. E por fim, pela própria exigência dos patrocinadores de melhor planejamento e viabilidade econômica dos projetos propostos, bem como dos retornos do investimento.

A premissa básica do Projeto GPE é, de um lado, viabilizar economicamente atividades importantes nos âmbitos de atuação da APM, e de outro, oferecer às empresas que a ele se integrar, maior visibilidade diante da classe oftalmológica. Ainda são oferecidas condições diferenciadas para participação em outros projetos da entidade, seja por benefícios financeiros, seja por privilégio em escolhas ou exclusividade na menção de suas marcas em espaços de comunicação da APM.

A única restrição para a aceitação de uma empresa no GPE é que ela deve patrocinar todos os projetos que compõem o portfólio, não sendo permitida a escolha de projetos individuais. Porém, não é descartada a postura ética das empresas, principalmente diante do exercício ilegal da medicina.

É importante salientar que mesmo não havendo a obrigatoriedade do lucro, tal como ocorre em organizações com fins lucrativos, a APM está sujeita a impactos financeiros. Desse modo, necessita de recursos financeiros para realizar suas ações, seja decorrente de recursos próprios ou oriundos de terceiros. Por exemplo, se uma campanha for realizada sem o devido planejamento orçamentário, pode comprometer a atuação da APM e, com isso, gerar impactos de ordem.

LACERDA, F. M.; BELFORT, A. C.; MARTENS, C. D. P. Manifestação da Orientação Empreendedora em uma organização sem fins lucrativos. Revista de

Empreendedorismo e Gestão de Pequenas Empresas, v.4, n.2, 2015. 
Em 2010, a APM iniciou a implementação do Sistema de Gestão da Qualidade (ISO 9001:2008), buscando a melhoria contínua da qualidade dos processos administrativos para melhor satisfação dos stakeholders e o cumprimento eficaz de sua missão principal, recebendo a certificação em 2011. Como é possível observar, a busca e adoção de novos processos gerenciais caracterizam a manifestação da dimensão inovatividade.

Com base no relato das ações realizadas pela APM diante das suas necessidades ou busca pelas oportunidades (motivação, processos e resultados), - Quadro 4 sintetiza aquelas que permitem analisar a manifestação da OE nas dimensões inovatividade, proatividade e assunção de riscos, de acordo com as subdimensões propostas por Morris, Webb e Franklin (2011).

Quadro 4 - Orientação Empreendedora na APM analisada

\begin{tabular}{|c|c|l|}
\hline Dimensão & $\begin{array}{c}\text { Subdimensão } \\
\text { (ênfase da } \\
\text { dimensão) }\end{array}$ & Práticas identificadas nas ações da APM \\
\hline \multirow{4}{*}{ Inovatividade } & Missão principal & $\begin{array}{l}\text { Sistema de Gestão da Qualidade; ações } \\
\text { educativas e aprimoramento do ensino da } \\
\text { especialidade. }\end{array}$ \\
\cline { 2 - 3 } & $\begin{array}{c}\text { Novas fontes de } \\
\text { receita }\end{array}$ & Captação de recursos privado e público. \\
\cline { 2 - 3 } Proatividade & Receita e missão & Ações conjuntas com a indústria e o governo. \\
\cline { 2 - 3 } & Objetivo social & Pesquisa, ensino e defesa profissional. \\
\cline { 2 - 3 } & Financeiro & $\begin{array}{l}\text { Portfólio de Projetos do GPE e ações com } \\
\text { outras associações médicas e não médicas. }\end{array}$ \\
\hline \multirow{4}{*}{$\begin{array}{c}\text { Assunção de } \\
\text { riscos }\end{array}$} & Impacto social & $\begin{array}{l}\text { Ações políticas e jurídicas em defesa da } \\
\text { saúde ocular da população e de atuação } \\
\text { médica. }\end{array}$ \\
\cline { 2 - 3 } & Perda financeira & $\begin{array}{l}\text { Açóes entre associações médicas e não } \\
\text { médicas }\end{array}$ \\
\cline { 2 - 3 } & $\begin{array}{l}\text { Impacto nos } \\
\text { stakeholders }\end{array}$ & $\begin{array}{l}\text { Campanhas voluntárias e de políticas públicas } \\
\text { de saúde. }\end{array}$ \\
\hline
\end{tabular}

Fonte: Elaborado pelos autores.

Para Morris, Webb e Franklin (2011), há uma expectativa de que possam existir relações entre as subdimensões. Nesse sentido, entre as ações apresentadas, algumas merecem ser retomadas para caracterizar certa relação entre as subdimensões.

LACERDA, F. M.; BELFORT, A. C.; MARTENS, C. D. P. Manifestação da Orientação Empreendedora em uma organização sem fins lucrativos. Revista de

Empreendedorismo e Gestão de Pequenas Empresas, v.4, n.2, 2015. 
Na dimensão inovatividade, o congresso anual é uma importante ação para o ensino da especialidade médica (missão principal) e para a captação de recursos financeiros com a venda de espaços comerciais (novas fontes de receitas). Através de ações educativas (missão principal) com recursos financeiros de órgão públicos para campanhas de prevenção e cuidados com a visão (receita e missão), igualmente caracteriza-se a dimensão inovatividade.

Já as subdimensões da proatividade se relacionam em algumas ações de defesa profissional (objetivo social), que fazem parte do portfólio de projetos do GPE (financeiro), disponibilizando, por exemplo, o código de ética médica comentado aos interessados (stakeholders).

Para a dimensão assunção de riscos, a relação entre as subdimensões pode ser verificada pelas ações políticas de um fórum periódico, devido à preocupação com a saúde ocular da população (impacto social), porém, correndo o risco de não contar com a participação e apoio da própria classe médica e de outras organizações (impacto nos stakeholders), podendo ainda ter que recorrer a agentes públicos e privados para sua realização (perda financeira).

A análise dos resultados apresentados e sintetizados no Quadro 4 permite concluir que entre as características de cada tipologia propostas por Morris, Webb e Franklin (2011), conforme Figura 1 anteriormente apresentada, para ilustrar a natureza multifacetada da OE no contexto sem fins lucrativos, a APM realiza ações que a caracteriza como uma organização "socialmente e comercialmente empreendedora", ou seja, o quadrante quatro.

A APM, com foco na sua missão e iniciativas sociais, bem como na realização de suas ações e relações comerciais com organizações públicas e privadas, tem enfatizado o empreendedorismo. Também vem realizando diversas iniciativas que permitiram identificar todas as subdimensões que captam o significado do empreendedorismo e da OE por meio das dimensões inovatividade, proatividade e assunção de riscos. Pelo empreendedorismo social, destacaram-se as ações educativas, de pesquisa, ensino e defesa profissional, e as em defesa da saúde da população. Pelo empreendedorismo comercial, as ações conjuntas com o setor privado e público e a sistematização de um portfólio de projetos para LACERDA, F. M.; BELFORT, A. C.; MARTENS, C. D. P. Manifestação da Orientação Empreendedora em uma organização sem fins lucrativos. Revista de Empreendedorismo e Gestão de Pequenas Empresas, v.4, n.2, 2015. 
a captação de novas fontes de receita, bem como as parcerias com outras associações médicas e não médicas foram evidenciadas.

Por fim, esse resultado vai ao encontro das expectativas de Morris, Webb e Franklin (2011), quanto à necessidade de uma melhor compreensão do contexto das OSFLs ao se analisar a manifestação da OE pela abordagem convencional (MILLER, 1983; COVIN; SLEVIN, 1989), isto é, sem considerar as peculiaridades inerentes ao contexto não lucrativo e, principalmente, com o foco na missão social.

\section{Considerações finais}

O presente trabalho objetivou analisar a manifestação da orientação empreendedora nas ações de uma organização sem fins lucrativos, notadamente, uma Associação de Profissionais Médicos, à luz do modelo de Morris, Webb e Franklin (2011).

Por meio das ações realizadas pela APM, foi possível caracterizar a manifestação do constructo unidimensional da $\mathrm{OE}$, ou seja, das dimensões inovatividade, proatividade e assunção de riscos. Tal fato pode ser constatado a partir da análise dos resultados sintetizada no Quadro 4, onde é possível verificar que a cada ação realizada pela APM, compreende uma subdimensão e, por conseguinte, uma dimensão da OE é caracterizada.

Nesse sentido, pode-se afirmar que a organização estudada busca agir de forma empreendedora, principalmente ao realizar ações que visam à geração e maior gestão interna de seus recursos financeiros, além de uma constante atuação diante das necessidades sociais do seu campo de atuação (BADELT, 1997; DEES, 1998; PEARCE; FRITZ; DAVIS, 2010; ZAHRA et al., 2009).

Uma importante contribuição desse estudo diz respeito ao fato de que, desde o surgimento do empreendedorismo no ambiente corporativo, poucos estudos têm sido realizados acerca da OE no contexto não lucrativo. Por outro lado, verifica-se que a $O E$ manifesta-se também em organizações sem fins LACERDA, F. M.; BELFORT, A. C.; MARTENS, C. D. P. Manifestação da Orientação Empreendedora em uma organização sem fins lucrativos. Revista de

Empreendedorismo e Gestão de Pequenas Empresas, v.4, n.2, 2015. 
lucrativos, evidenciando, assim, a existência de campo de pesquisa para esse tema.

Já em relação ao modelo de Morris, Webb e Franklin (2011), foi possível contribuir com a verificação da existência de relações entre as subdimensões no caso estudado, conforme a expectativa dos autores.

Como os resultados deste estudo decorrem da análise e reflexão a partir da literatura visitada, complementados pelo caso analisado, caracteriza-se a existência de certo grau de subjetividade, reforçando a necessidade de estudos mais aprofundados sobre o tema.

Assim, sugere-se a realização de outros estudos que explorem a manifestação da OE em organizações sem fins lucrativos à luz do modelo de Morris, Webb e Franklin (2011), incluindo a análise da relação entre as subdimensões, sobretudo em se considerando o cenário brasileiro que compõe o setor.

Propõe-se, portanto, realizar estudos multicasos, mais amplos, tendo por base o resultado aqui obtido, podendo ser agregada na análise as dimensões autonomia e agressividade competitiva, que compõem o constructo multidimensional da OE proposto por Lumpkin e Dess (1996), como adotado nos estudos de Pearce, Fritz e Davis (2010) e Voss, Voss e Moorman (2005). Adicionalmente, sugere-se a entrevista como procedimento de coleta de dados, caso a observação não seja possível, como neste estudo.

As limitações do presente estudo dizem respeito ao fato de tratar-se de caso único, não sendo admitido extrapolar os resultados ou generalizá-los, bem como uma possibilidade de viés na observação participante de um dos autores. Porém, tem-se a expectativa de que com a triangulação dos dados, essa limitação tenha sido minimizada.

Nesta perspectiva, novos questionamentos surgiram a partir da realização deste estudo: no caso de outra organização sem fins lucrativos (não Associação de Profissionais Médicos), a manifestação da OE ocorre da mesma forma? É possível criar um modelo que possa ser aplicado a qualquer tipo de organização sem fins lucrativos que identifique as ações que norteiam as subdimensões e LACERDA, F. M.; BELFORT, A. C.; MARTENS, C. D. P. Manifestação da Orientação Empreendedora em uma organização sem fins lucrativos. Revista de

Empreendedorismo e Gestão de Pequenas Empresas, v.4, n.2, 2015. 
dimensões da OE? Como a classificação de uma OSFL em um dos quadrantes do modelo de Morris, Webb e Franklin (2011) poderia contribuir para o direcionamento estratégico de tal organização?

Por fim, esses e outros questionamentos podem ser a base para o desenvolvimento de novos estudos empíricos, no intuito de verificar até que ponto ocorre a manifestação da OE em uma organização sem fins lucrativos à luz do modelo de Morris, Webb e Franklin (2011), bem como sua contribuição na formulação de estratégias para a busca de oportunidades e a geração de receita visando sustentar suas ações sociais, comerciais ou institucionais.

\section{Referências:}

BADELT, C. Entrepreneurship theories of the non-profit sector. Voluntas: International Journal of Voluntary and Nonprofit Organizations, v. 8, n. 2, p. 162-178, 1997.

COVIN, J. G.; LUMPKIN, G. T. Entrepreneurial orientation theory and research: Reflections on a needed construct. Entrepreneurship Theory and Practice, v. 35, n. 5, p. 855-872, 2011.

COVIN, J. G.; SLEVIN, D. P. Strategic management of small firms in hostile and benign environments. Strategic Management Journal, v. 10, n. 1, p. 75-87, 1989.

DACIN, P. A.; DACIN, M. T.; MATEAR, M. Social Entrepreneurship: why we don't need a new theory and how we move forward from here. Academy of Management Perspectives, p. 37-57, 2010.

DEES, J. G. Enterprising nonprofits. Harvard Business Review, v. 76, n. 1, p. 5566, 1998.

FASFIL. As fundações privadas e associações sem fins lucrativos no Brasil. (IBGE, IPEA, ABONG, GIFE, \& SGP, Eds.) (p. 178). Brasília: IBGE, 2012.

FERNANDES, D. V. D. H.; SANTOS, C. P. Orientação Empreendedora: um estudo sobre as consequências do empreendedorismo nas organizações. RAEeletrônica, v. 7, n. 1, Art. 6, 2008.

LACERDA, F. M.; BELFORT, A. C.; MARTENS, C. D. P. Manifestação da Orientação Empreendedora em uma organização sem fins lucrativos. Revista de Empreendedorismo e Gestão de Pequenas Empresas, v.4, n.2, 2015. 
FRANÇA, A. B.; SARAIVA, J.; HASHIMOTO, M. Orientação empreendedora como indicador do grau de empreendedorismo corporativo: fatores que caracterizam os intraempreendedores e influenciam sua percepção. Revista de Empreendedorismo e Gestão de Pequenas Empresas, v.1, n. 3, p. 78-103, 2012.

FREITAS, H.; MARTENS, C. D. P.; BOISSIN, J. P.; BEHR, A. Elementos para guiar ações visando à orientação empreendedora em organizações de software. Revista de Administração - RAUSP, v. 47, n. 2, p. 163-179, 2012.

GEORGE, B. A.; MARINO, L. The epistemology of entrepreneurial orientation: conceptual formation, modeling, and operationalization. Entrepreneurship Theory \& Practice, v.35, n.5, p. 989-1024, 2011.

GRÉGOIRE, D. A.; NOËL, M. X.; DÉRY, R.; BÉCHARD, J-P. Is there conceptual convergence in entrepreneurship research? A co-citation analysis of frontiers of entrepreneurship research 1981-2004. Entrepreneurship Theory \& Practice, v.30, n.3, p. 337-373, 2006.

HASHIMOTO, M.; BELÊ, E. A importância dos gerentes na orientação empreendedora. Revista de Empreendedorismo e Gestão de Pequenas Empresas, v.3, n.2, p. 120-144, 2014.

IBGE. INSTITUDO BRASILEIRO DE GEOGRAFIA E ESTATÍSTICA. XII Censo Demográfico, 2010.

LUMPKIN, G. T.; DESS, G. G. Clarifying the entrepreneurial orientation construct and linking it to performance. Academic of Management Review, v. 21, n. 1, p. 135-172, 1996.

LUMPKIN, G. T.; MOSS, T. W.; GRAS, D. M.; KATO, S.; AMEZCUA, A. S. Entrepreneurial processes in social contexts: how are they different, if at all? Small Business Economics, v.40, n.3, p. 761-783, 2011.

MALHOTRA, N. K. Pesquisa de Marketing: uma orientação aplicada. 4 ed.. Porto Alegre: Bookman, 2006.

LACERDA, F. M.; BELFORT, A. C.; MARTENS, C. D. P. Manifestação da Orientação Empreendedora em uma organização sem fins lucrativos. Revista de Empreendedorismo e Gestão de Pequenas Empresas, v.4, n.2, 2015. 
MARTENS, C. D. P.; FREITAS, H.; ANDRES, R. Desenvolvimento da orientação empreendedora em empresas de software: proposições preliminares. REAd, $v$. 69, n. 2, p. 424-450, 2011.

MARTINS, G. A.; THEÓPHILO, C. R. Metodologia da investigação cientifica para ciências sociais aplicadas. 2 ed. São Paulo: Atlas, 2009.

MILLER, D. The correlates of entrepreneurship in three types of firms. Management Science, v. 29, n. 7, p. 770-791, 1983.

MORRIS, M. H.; COOMBES, S.; SCHINDEHUTTE, M.; ALLEN, J. Antecedents and Outcomes of Entrepreneurial and Market Orientations in a Non-profit Context: Theoretical and Empirical Insights. Journal of Leadership \& Organizational Studies, v. 13, n. 4, p. 12-39, 2007.

MORRIS, M. H.; WEBB, J. W.; FRANKLIN, R. J. Understanding the Manifestation of Entrepreneurial Orientation in the Nonprofit Context. Entrepreneurship Theory and Practice, v. 35, n. 5, p. 947-971, 2011.

MORT, G S; WEERAWARDENA, J; CARNEGIE, K. Social entrepreneurship: towards conceptualization. International Journal of Nonprofit \& Voluntary Sector Marketing, v. 8, n. 1, 2003.

PEARCE, J. A.; FRITZ, D. A.; DAVIS, P. S. Entrepreneurial orientation and the performance of religious congregations as predicted by rational choice theory. Entrepreneurship Theory and Practice, v. 34, n. 1, p. 219-248, 2010.

RAUCH, A.; WIKLUND, J.; LUMPKIN, G. T.; FRESE, M. Entrepreneurial orientation and business performance: An assessment of past research and suggestions for the future. Entrepreneurship Theory \& Practice, v. 33, n. 3, p. 761-781, 2009.

SCHILDT, H. A.; ZAHRA, S. A.; SILLANPÄÄ, A. Scholarly communities in entrepreneurship research: a co-citation analysis. Entrepreneurship Theory \& Practice, v. 30, n. 3, p. 399-415, 2006.

SHANE, S.; VENKATARAMAN, S. The promise of entrepreneurship as a field of research. The Academy of Management Review, v. 25, n. 1, p. 217-226, 2000.

LACERDA, F. M.; BELFORT, A. C.; MARTENS, C. D. P. Manifestação da Orientação Empreendedora em uma organização sem fins lucrativos. Revista de Empreendedorismo e Gestão de Pequenas Empresas, v.4, n.2, 2015. 
SHORT, J. C.; KETCHEN, D. J., Jr.; COMBS, J. G.; IRELAND, R. D. Research Methods in Entrepreneurship - Opportunities and challenges. Organizational Research Methods, v. 13, n. 1, p. 6-15, 2010.

SILVA, M. A. O. M.; GOMES, L. F. A. M.; CORREIA, M. F. Cultura e Orientação Empreendedora: uma Pesquisa Comparativa entre Empreendedores em Incubadoras no Brasil e em Portugal. Revista de Administração Contemporânea, v. 13, n. 1, p. 57-71, 2009.

SLEVIN, D. P.; TERJESEN, S. A. Entrepreneurial orientation: reviewing three papers and implications for further theoretical and methodological development. Entrepreneurship Theory \& Practice, v. 35, n. 5, p. 973-987, 2011.

VOSS, Z. G.; VOSS, G. B.; MOORMAN, C. An empirical examination of the complex relationships between entrepreneurial orientation and stakeholder support. European Journal of Marketing, v. 39, n. 6, p. 1132-1150, 2005.

WALES, W.; MONSEN, E.; MCKELVIE, A. The organizational perva-siveness of entrepreneurial orientation. Entrepreneurship Theory and Practice, v. 35, n. 5, p. 895-923, 2011.

YIN, R. K. Estudo de Caso: planejamento e métodos. 4 ed. Porto Alegre: Bookman, 2010.

ZAHRA, S. A.; GEDAJLOVIC, E.; NEUBAUM, D.; SHULMAN, J. A typology of social entrepreneurs: Motives, search processes and ethical challenges. Journal of Business Venturing, v. 24, n. 5, p. 519-532, 2009.

LACERDA, F. M.; BELFORT, A. C.; MARTENS, C. D. P. Manifestação da Orientação Empreendedora em uma organização sem fins lucrativos. Revista de Empreendedorismo e Gestão de Pequenas Empresas, v.4, n.2, 2015. 